Abstract 24 Table 2 Adults undergoing ICD implants in 'Other' Category between 2016 and 2020

\begin{tabular}{lll}
\hline 2016-2020 & & \\
\hline Anomalous coronary artery & 2 & Secondary (2) \\
Pulmonary atresia, VSD, MAPCAs, central PA shunt & 1 & Primary \\
AVSD & 1 & Primary \\
VSD & 1 & Primary \\
Ebstein's & 2 & Primary (2) \\
PS & 1 & Primary \\
Double inlet LV, double outlet RV & 1 & Secondary \\
Coarctation and bicuspid aortic valve & 1 & Primary \\
\hline
\end{tabular}

between surgery and ICD implant was 23 years for both indications.

Figures $2 \mathrm{~A}$ and $2 \mathrm{~B}$ show the underlying condition in those who had an ICD implanted over the 15 year period. These demonstrate a decline in ICD implantation for those with either Tetralogy of Fallot or Transposition of the Great Arteries (TGA and CCTGA) in the last 5 years compared with data from $2006-2015 ; 52 \%$ to $41 \%$, and $30 \%$ to $22 \%$ respectively. The number of patients undergoing ICD implantation with 'Other' underlying congenital heart disease is shown to have increased from $18 \%$ of overall cases in 20062015 , to $37 \%$ of overall cases in 2016 to 2020 .

Tables 1 and 2 detail the 'Other' conditions and the indication for device.

Conclusions Despite the number of ACHD patients in the population increasing significantly over the same time period, annual rates of ICD implantation in our centre have reduced over time, especially over the last 5 years. The reason for this decline may reflect historical improvements in cardiac surgical techniques and the timing of surgery, thereby resulting in preserved ventricular function and less ventricular scar. Close, regular follow up in the modern era will likely result in early detection and treatment of structural problems which might be expected to reduce the incidence of serious arrhythmia. Regular surveillance would also be expected to allow for earlier detection of non-sustained ventricular arrhythmia, resulting in the initiation of anti-arrhythmic therapy that might prevent or delay the need for an ICD.

Conflict of Interest None

\section{ADVANCE CARE PLANNING IN PATIENTS WITH SYSTEMIC RIGHT VENTRICULAR FAILURE}

${ }^{1}$ Alice Copley, ${ }^{1}$ Sarah Gardner, ${ }^{1}$ Eleanor Joy, ${ }^{1} J a m e s$ Oliver, ${ }^{1}$ Kate English, ${ }^{2}$ Damien Cullington, 'Karina Gopaul. 'Leeds Teaching Hospitals NHS Trust, Leeds, UK; ${ }^{2}$ North West Congenital Cardiac Service

\subsection{6/heartjnl-2021-BCS.25}

Introduction Patients with transposition of the great arteries (ccTGA) and patients with transposition of the great arteries who had palliative surgery (Mustard/Senning procedures) often have progressive functional deterioration of the systemic right ventricle (sRV) and develop heart failure from the third or fourth decade of life. ${ }^{1}$ End stage heart failure requires an integrated approach and advance care planning (ACP) ${ }^{2}$ with ACHD cardiologists working alongside specialist heart failure and palliative care teams. We describe current practice with regards to ACP and palliative care referrals in patients with sRV at a tertiary referral centre.

Methods Patients with ccTGA, Mustard or Senning procedures who were under active follow up from 2016 to 2021 were retrospectively analysed $(n=122)$. Clinical and echocardiographic data were extracted from hospital electronic records and screened for factors which should prompt the consideration of palliative care referral and ACP as specified in prior guidance. $^{2}$ These were; an episode of decompensation within 6 months despite optimal medical therapy, malignant arrhythmias, cardiac cachexia, frequent or continued intravenous therapies, poor quality of life (QoL), or progressive functional decline with dependence in activities of daily living and New York Heart Association (NYHA) IV symptoms.

Results Baseline information is summarised in table 1. 7 patients had ACP (figure 1). 2 occurred during hospital admission in NYHA III patients with more than 1 episode of decompensation in 6 months despite optimal medical therapy, need for frequent intravenous therapy and chronic poor QoL. Cardiopulmonary resuscitation, implanted cardiac defibrillator deactivation and future care preferences were discussed. 5 patients had ACP as an outpatient who were NYHA I or II, which were patient initiated $(n=3)$ and clinician initiated in response to progressive functional decline $(n=1)$ and no identifiable prompt $(n=1) .5$ patients died during the data collection period (median age 41 years), 1 of which had advanced heart failure, discussed ACP and was referred to palliative care. 2 patients did not have ACP or palliative care input, however did meet the criteria for doing so (table 2).

Abstract 25 Table 1 Baseline information and demographic data

\begin{tabular}{|l|l|}
\hline Age (mean \pm std dev) years & $39( \pm 9)$ \\
\hline CCTGA & $37(30.3 \%)$ \\
\hline Mustard procedure & $37(30.3 \%)$ \\
\hline Senning procedure & $48(39.3 \%)$ \\
\hline Presence of implanted cardiac defibrillator & $20(16.3 \%)$ \\
\hline 1 or more comorbidities* unrelated to ACHD diagnosis & $45(36.6 \%)$ \\
\hline Systemic RV function assessed by echocardiography \\
\hline Mildly impaired & $46(37.7 \%)$ \\
\hline Moderately impaired & $48(39.3 \%)$ \\
\hline Severely impaired & $17(13.9 \%)$ \\
\hline \\
-Major comorbidities involving a system, organ or multisystem disorder. "Visual assessment graded by \\
experienced congenital sonographers. Data was not available for 11 patients due to limited imaging.
\end{tabular}

Abstract 25 Table 2 Patient features and factors meeting criteria for ACP or referral to palliative care in patients that died

\begin{tabular}{|l|l|l|l|l|l|}
\hline & $\begin{array}{l}\text { Cause or mode of } \\
\text { death }\end{array}$ & $\begin{array}{l}\text { Age of } \\
\text { death/ } \\
\text { years }\end{array}$ & $\begin{array}{l}\text { Advanced } \\
\text { heart failure" }\end{array}$ & $\begin{array}{l}\text { Had ACP or } \\
\text { palliative } \\
\text { care referrat? }\end{array}$ & $\begin{array}{l}\text { Factors meeting criteria for ACP or } \\
\text { referral to palliative care }\end{array}$ \\
\hline 1 & $\begin{array}{l}\text { Cardiac arrest, } \\
\text { arrhythmia" }\end{array}$ & 73 & No & No & $\begin{array}{l}\text { Recurrent atrial arrhythmias } \\
\text { NYHA II }\end{array}$ \\
\hline 2 & $\begin{array}{l}\text { End stage heart } \\
\text { failure }\end{array}$ & 53 & Yes & Yes & $\begin{array}{l}\text { Recurrent hospital admissions } \\
\text { requiring IV treatment } \\
\text { Progressive functional decline and } \\
\text { QoL } \\
\text { Dependence in activities of daily } \\
\text { living } \\
\text { NYHA IV }\end{array}$ \\
\hline 3 & $\begin{array}{l}\text { Cerebrovascular } \\
\text { event }\end{array}$ & 41 & $\begin{array}{l}\text { Yes - } \\
\text { ventricular } \\
\text { assist device }\end{array}$ & No & $\begin{array}{l}\text { IV diuretic therapy frequency } \\
\text { increased } \\
\text { Progressive functional decline and } \\
\text { QoL pre MCS } \\
\text { NYHA III }\end{array}$ \\
\hline 4 & Cardiac arrest"* & 38 & No & No & $\begin{array}{l}\text { Progressive functional decline, } \\
\text { NYHA III }\end{array}$ \\
\hline 5 & $\begin{array}{l}\text { Acute } \\
\text { decompensated } \\
\text { heart failure }\end{array}$ & 28 & No & No & $\begin{array}{l}\text { Frequent admissions with } \\
\text { decompensated HF requiring } \\
\text { intravenous diuretics } \\
\text { Progressive functional decline and } \\
\text { QoL limiting daily activities } \\
\text { NYHA III }\end{array}$ \\
\hline
\end{tabular}




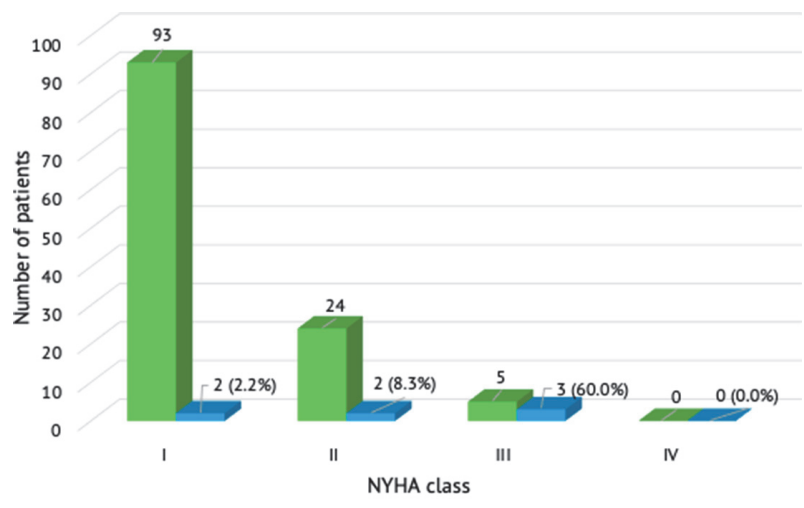

$\llbracket$ Total number of patients $₫$ Number who had ACP / palliative care referral (\%)

Abstract 25 Figure 1 Number of patients (\%) with sRV impairment who had ACP or palliative care input according to NYHA class

Conclusions In our cohort of patients with sRV, the majority of patients are NYHA class I and II with mild or moderately impaired sRV function. ACP occurred in $60 \%$ of patients with NYHA III symptoms. The timing of ACP or palliative care referral can be challenging due to the subjective under reporting of symptoms and risk of sudden death in this group. ACP discussions in the outpatient setting occurred irrespective of NYHA class severity and were mostly patient initiated. Early discussion is advocated in light of recent guidance ${ }^{3}$ recommending staged ACP to those who express an interest, or concurrently with planning interventions such as device implantation, heart transplant assessment, catheter interventions or cardiac surgery.

Conflict of Interest None

\section{REFERENCES}

1. Brida M, Diller GP, Gatzoulis MA. Systemic right ventricle in adults with congenital heart disease. Circulation 2018;137:508-518.

2. Jaarsma T et al. Advanced heart failure study group of the HFA of the ESC. Palliative care in heart failure: a position statement from the palliative care workshop of the Heart Failure Association of the European Society of Cardiology. Eur J Heart Fail 2009;11(5):433-43

3. Schwerzmann $\mathrm{M}$ et al. Recommendations for advance care planning in adults with congenital heart disease: a position paper from the ESC Working Group of Adult Congenital Heart Disease, the Association of Cardiovascular Nursing and Allied Professions (ACNAP), the European Association for Palliative Care (EAPC), and the International Society for Adult Congenital Heart Disease (ISACHD). European Heart Journal 2020;41(43):4200-4210.

\section{THE PROGNOSTIC ROLE OF EPICARDIAL ADIPOSE TISSUE IN AORTIC STENOSIS: INSIGHTS FROM A CARDIOVASCULAR MAGNETIC RESONANCE STUDY}

${ }^{1}$ Madeline White, ${ }^{2}$ Vassilios Vassiliou, 'Ioannis Merinopoulos, ${ }^{3}$ Claire E Raphael, ${ }^{1}$ Pankaj Garg, ${ }^{4}$ Sanjay Prasad. ${ }^{1}$ University of East Anglia, Norwich, UK; ${ }^{2}$ Norwich Medical School, University of East Anglia; ${ }^{3}$ Cleveland Clinic, US; ${ }^{4}$ Imperial College London

\subsection{6/heartjnl-2021-BCS.26}

Introduction Epicardial adipose tissue (EAT) is a biologically active type of visceral fat between the pericardium and the myocardium. It is thought to have both cardioprotective and harmful functions but what mechanisms regulate this balance remain unclear. Limited literature exists on its prognostic role in aortic stenosis (AS). We investigated the association of EAT and survival in patients with AS.

Methods Consecutive patients $(n=119$, age $75.7 \pm 10.1$ years, $70.6 \%$ male) with AS who underwent late-gadolinium contrast enhanced cardiovascular magnetic resonance (LGE-CMR) on an $1.5 \mathrm{~T}$ Siemens were identified retrospectively. EAT was quantified on CMR and indexed to myocardial mass (Circle CVI, Calgary, Canada) (figure 1). Survival status was acquired from the Office of National Statistics. Univariate and multivariate linear regression analyses identified predictors of EAT and mortality.

Results Over a mean follow up of $4.2 \pm 2.4$ years, 61 (51\%) patients died. On univariate analysis, age (HR 1.050, 95\% CI 1.018-1.082, $\mathrm{p}=0.002$ ), NYHA class (HR 1.421, 95\% CI 1.004-2.012, $\mathrm{p}=0.048)$, indexed left ventricular end-diastolic volume (LVEDV) (HR 1.009, 95\% CI 1.001-1.017, p=0.025), indexed left ventricular end-systolic volume (LVESV) (HR 1.010, 95\% CI 1.002-1.018, p=0.014), LnNT-proBNP (HR $1.265,95 \%$ CI $1.035-1.547, \mathrm{p}=0.022)$, high sensitivity troponin I (HR 1.000, 95\% CI 1.000-1.000, p=0.001), osteopontin (HR 1.002, 95\% CI 1.001-1.003, $\mathrm{p}=0.001)$, osteoprotegerin (HR 1.143, 95\% CI 1.052-1.242, p=0.002), ST2 (HR 1.013, 95\% CI 1.006-1.021, $\mathrm{p}=0.001$ ) and albumin (HR 0.931, 95\% CI $0.887-0.977, p=0.004)$ were all associated with increased mortality. EAT volume indexed to myocardial mass was not

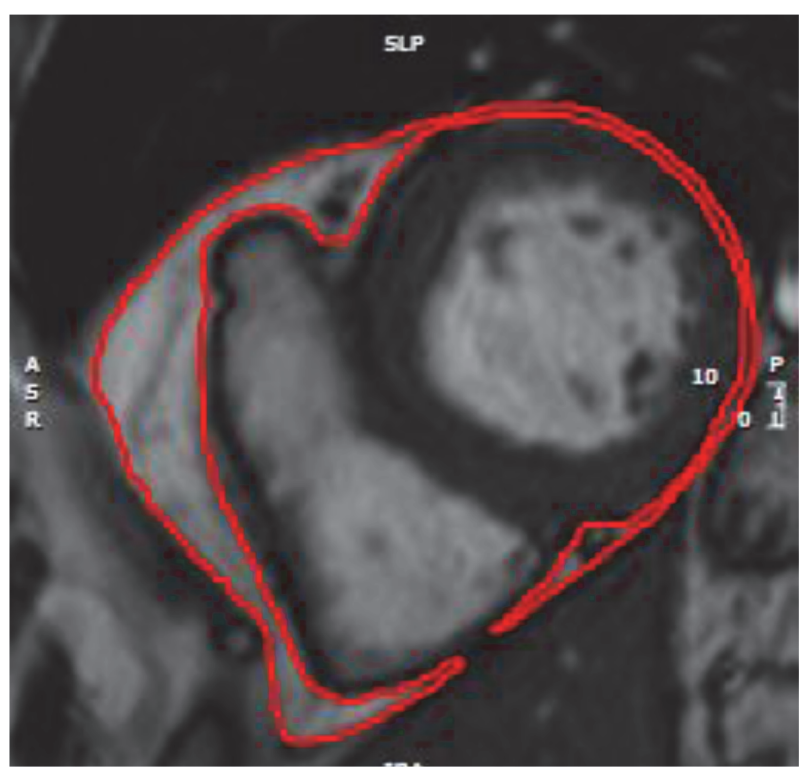

Abstract 26 Figure 1 Quantification of epicardial adipose tissue (EAT) using cardiovascular magnetic resonance (CMR) imaging in the $S A X$ view with the heart in diastole. Following tracing in each SAX view a 3D model of EAT was created

Abstract 26 Table 1 Forwardstepwise multivariate linear regression analysis

\begin{tabular}{llll}
\hline & HR & $95 \% \mathrm{Cl}$ & p-value \\
\hline hsTnl $(\mathrm{ng} / \mathrm{L})$ & 1.001 & $1.000-1.001$ & 0.166 \\
ST2 $(\mathrm{ng} / \mathrm{mL})$ & 1.020 & $1.003-1.037$ & 0.022 \\
LnNT-proBNP & 1.285 & $1.036-1.594$ & 0.022 \\
Any intervention & 0.308 & $0.159-0.597$ & $<0.001$ \\
(TAVI or AVR) & & & \\
\hline
\end{tabular}

Table 1 showsthat in multivariate analysis, any intervention (TAVI or AVR) remained the onlysignificant predictor of increased survival. ST2 and LnNT-proBNP remained theonly significant predictors of poor mortality. HR:hazard ratio; Cl: confidence interval; hsTnl: highsensitivity troponin I; ST2:suppression of tumorigenicity 2; NT-proBNP: N-terminal prohormone ofbrain natriuretic peptide; TAVI: transcatheter aortic valve intervention; AVR:aortic valve replacement 